\title{
Perspectives on reasons of medication nonadherence in psychiatric patients
}

\author{
This article was published in the following Dove Press journal: \\ Patient Preference and Adherence \\ 13 January 2015 \\ Number of times this article has been viewed
}

\author{
Derya Güliz Mert' \\ Nergiz Hacer Turgut ${ }^{2}$ \\ Meral Kelleci ${ }^{3}$ \\ Murat Semiz ${ }^{4}$ \\ 'Department of Psychiatry, Faculty \\ of Medicine, Cumhuriyet University, \\ ${ }^{2}$ Department of Pharmacology, \\ Faculty of Pharmacy, Cumhuriyet \\ University, ${ }^{3}$ Department of Psychiatric \\ Nursing, Faculty of Health Sciences, \\ Cumhuriyet University, Sivas, Turkey; \\ ${ }^{4}$ Department of Psychiatry, Faculty \\ of Medicine, University of Osmangazi, \\ Tokat, Turkey
}

Purpose: This study was carried out to evaluate factors resulting in medication nonadherence within 6 months before admission to the psychiatric service of our hospital for bipolar disorder, schizophrenia/schizoaffective disorder, depression, and other psychiatric diseases.

Patients and methods: Two hundred and three patients admitted to the Psychiatry Service of the Medical Faculty were included in this study. Sociodemographic parameters and clinical findings within 6 months before admission and patients' views on reasons of medication nonadherence were examined.

Results: Patients were classified into four groups according to their diagnosis: bipolar disorder $(n=68,33.5 \%)$, schizophrenia/schizoaffective disorder $(n=59,29.1 \%)$, depression $(\mathrm{n}=39,19.2 \%)$, and others $(\mathrm{n}=37,18.2 \%)$. The ratio of medication nonadherence was higher in the bipolar disorder group when compared to the groups with schizophrenia/schizoaffective disorder, depression, and other disorders $(12.1 \%, 18.2 \%$, and $24.2 \%$ vs $45.5 \%)$; however, the ratio of medication nonadherence was similar in schizophrenia/schizoaffective disorder, depression, and the others group. In logistic regression analysis, irregular follow-up (odds ratio [OR]: 5.7; 95\% confidence interval [CI]: 2.92-11.31) and diagnosis (OR: 1.5; 95\% CI: 1.07-1.95) were determined to be important risk factors for medication nonadherence. The leading factors for medication nonadherence were: "not willing to use medication", "not accepting the disease", and "being disturbed by side effects" in the bipolar disorder group, "not accepting the disease" in the schizophrenia/schizoaffective disorder group, "feeling well" in the depression group, and "being disturbed by side effects" in the other diseases group.

Conclusion: Medication nonadherence is an important problem in psychiatric patients and should be dealt with by taking into account the diagnosis, attendance to follow-up appointments, and the patient's attitude. Ensuring regular attendance to follow-up appointments, adjusting the management plan according to the diagnosis, and improving their thoughts about resistance to medication can be beneficial in terms of medication adherence.

Keywords: bipolar disorder, schizophrenia, schizoaffective disorder, depression, patient's attitude

\section{Introduction}

The World Health Organization has reported the ratio of medication adherence as around $50 \%$ in people with a chronic disease. ${ }^{1}$ Nonadherence to treatment is a major problem in psychiatric patients; ${ }^{2}$ a recent review has stated a ratio of $20 \%-60 \%$ in psychiatric patients. ${ }^{3}$ Treatment nonadherence can be in the form of not taking the medication at the recommended dose and frequency, not taking the medication at all, ${ }^{1}$ and irregular attendance to follow-up appointments or not attending at all. The most important and highly encountered form of medication nonadherence is where a patient does not follow the recommended dose and frequency. The ratio of
Correspondence: Derya Güliz Mert Department of Psychiatry, Faculty of Medicine, Cumhuriyet University, Sivas 58140 , Turkey

Tel +3462580000

Email drgulizaksoy@yahoo.com 
nonadherence has been reported as $40 \%-60 \%$ for antipsychotics, $18 \%-56 \%$ for mood stabilizers, and 30\%-97\% (63\% on average) for antidepressants. ${ }^{4-6}$ Moreover, in studies evaluating medication adherence based on diagnosis, the ratio of nonadherence to medication has been shown to be $12 \%-64 \%$ in patients with bipolar disorders, $11 \%-80 \%$ in patients with schizophrenia, and $30 \%-60 \%$ in patients with depression. ${ }^{7-9}$

There are many factors leading to medication nonadherence in psychiatric patients, including lack of insight into having an illness, distress associated with side effects, disturbing side effects affecting quality of life, lack of family and social support, insufficient information on the disease and treatment, and substance abuse or addiction. ${ }^{1,7-10}$ The Diagnostic and Statistical Manual of Mental Disorders (DSM)-V describes many conditions for medication nonadherence, including overweight or obesity, malingering, wandering associated with a mental disorder, and borderline intellectual functioning. ${ }^{11}$ Medication nonadherence is one of the major avoidable reasons causing relapses and morbidity. ${ }^{12}$ For this reason, reasons of nonadherence should be examined while evaluating patients. History of nonadherence, alcohol or substance use during symptom-free periods, medication doses, multiple medication use, side effects, and therapeutic alliance should be investigated in detail. ${ }^{3}$ As medication nonadherence frequently causes exacerbations, relapses, harmful behavior to oneself or one's environment, suicide and rehospitalization, it has negative impacts both on patients and their family and society. ${ }^{3,13}$ Hospitalization can be associated with medication nonadherence in $20 \%-25 \%$ of psychiatric patients. ${ }^{8}$

Studies on medication nonadherence, which has an important role in the treatment of psychiatric diseases, and factors associated with nonadherence usually address a single diagnosis group. In the literature, there are an insufficient number of studies comparing different diagnosis groups in terms of medication nonadherence. Moreover, studies assessing the contribution of patients' features and disease-related factors to medical nonadherence are not sufficient either. Results to be obtained on reason of medication nonadherence may have a great impact on inpatients' treatment and outpatient follow-ups. In the present study, factors resulting in medication nonadherence within 6 months before admission to the psychiatric service of our hospital for bipolar disorder, schizophrenia/schizoaffective disorder, depression, and other psychiatric disorders were evaluated from a multidimensional approach.

\section{Patients and methods Study population}

The present cross-sectional study was conducted on patients hospitalized at the psychiatry clinic at our hospital for bipolar disorder, schizophrenia and schizoaffective disorders, depression, and other psychiatric disorders. Before the study was conducted, the approval of the Human Research Ethics Committee was obtained. All patients receiving treatment between October 2013 and February 2014 were asked to participate in the study, and those willing to participate were included in the study upon receiving consent. The term covering 6 months before the study was evaluated. Those with a psychiatric comorbid diagnosis, mental retardation, and illiterate patients were excluded from the study. Axis I disorders were assessed using the Structural Clinical Interview Diagnosis I (SCID-I) research version. ${ }^{14}$ Patients included in the study were classified into bipolar disorder, schizophrenia/ schizoaffective disorder, depression, and other disorder (such as adjustment disorder, anxiety disorder, dissociative disorder, substance abuse, or impulse control disorder - not otherwise specified) groups.

\section{Data collection tools}

A special form was prepared to collect demographic and clinical data. Patients were asked to fill in the form on the day they were discharged from the psychiatry service. Sociodemographic features (sex, age, education level, marital status, employment status, place of residence, and household); clinical features and those affecting the course of disease (onset of complaints, number of hospitalizations, presence of axis II diagnosis, additional physical disease, and cigarette/substance addiction); attendance to follow-up appointments within 6 months before admission; and reasons of medication nonadherence (not willing to use medication, not accepting the disease, being disturbed by side effects, feeling well, not knowing how long the medication would be taken, being not aware that the medication would be taken regularly, and other reasons) were examined through the said form. Not taking any medicine for at least 1 week during the 6-month term before the study was regarded as medication nonadherence. ${ }^{15}$ This data was supported by the data gathered from first-degree relatives and patient files. Non-attendance of at least $20 \%$ of the appointments during the 6 months before the study was regarded as not attending the regular polyclinic follow-ups. ${ }^{16}$ This data also was supported by the data gathered from first-degree relatives and patient files. 


\section{Statistical analysis}

Data were presented as mean \pm standard deviation (SD) and percentage and statistically evaluated by SPSS software (v22; IBM Corporation, Armonk, NY, USA). After descriptive analysis, independent variables thought to affect the dependent variable medication nonadherence, namely age, sex, marital status, education status, smoking, household, place of residence, irregular follow-up attendance, and diagnostic parameters, were analyzed by logistic regression test. The distribution of the items selected by the cases in a sevenitem question - multiple answer questions answered as yes/ no- examining the reasons of medication nonadherence was evaluated using multiple response analysis. $P<0.05$ was regarded as statistically significant.

\section{Results}

The average age of the patients was $36.7 \pm 13.2$ years. Sociodemographic features are shown in Table 1. Ninety-six (47.3\%) of the patients were married, 78 (38.4\%) were primary school graduates, and 145 (71.4\%) were unemployed. One hundred and thirty $(64.0 \%)$ of the patients were residing in downtown, while 97 (47.8\%) were living with their mother/father/sibling.

Table I Sociodemographic parameters

\begin{tabular}{|c|c|}
\hline Sociodemographic characteristics & n (\%) \\
\hline \multicolumn{2}{|l|}{ Sex } \\
\hline Female & $90(44.3)$ \\
\hline Male & $113(55.7)$ \\
\hline \multicolumn{2}{|l|}{ Marital status } \\
\hline Married & $96(47.3)$ \\
\hline Single & $75(36.9)$ \\
\hline Divorced & $22(10.8)$ \\
\hline Widow & $10(4.9)$ \\
\hline \multicolumn{2}{|l|}{ Education status } \\
\hline Primary school & $78(38.4)$ \\
\hline Secondary school & $40(19.7)$ \\
\hline High school & $59(29.1)$ \\
\hline University & $24(I I .8)$ \\
\hline \multicolumn{2}{|l|}{ Employment status } \\
\hline Unemployed & $145(7 \mid .4)$ \\
\hline Employed & $58(28.6)$ \\
\hline \multicolumn{2}{|l|}{ Place of residence } \\
\hline Village & $39(19.2)$ \\
\hline County & $34(16.7)$ \\
\hline City & $130(64.0)$ \\
\hline \multicolumn{2}{|l|}{ Households } \\
\hline Spouse/children & $82(40.4)$ \\
\hline Mother/father/sibling & $97(47.8)$ \\
\hline Nursery & $5(2.7)$ \\
\hline Alone & $17(9.0)$ \\
\hline Other & $2(0.1)$ \\
\hline
\end{tabular}

The median length of total hospitalization at the psychiatry service was 2 days (range: $0-20$ ), while the mean period for initiation of complaints was 2,776.5 $\pm 1,012.3$ days. There were 45 (22.2\%) cases with comorbid physical disease, $23(11.3 \%)$ patients with axis II diagnosis, and 20 $(9.9 \%)$ patients with lifelong substance abuse. Cases having a history of substance abuse stated that they had not used any substance during the 6-month term before hospitalization. Twenty-four $(61.1 \%)$ of the cases stated that they were smokers.

It was found that $104(51.2 \%)$ of the patients took their medicines regularly during the last 6 months, while 99 (48.8\%) patients experienced medication nonadherence. Patients were studied under four groups: bipolar disorder $(\mathrm{n}=68,33.5 \%)$, schizophrenia/schizoaffective disorder $(\mathrm{n}=59$, $29.1 \%)$, depression $(n=39,19.2 \%)$, and other $(n=37,18.2 \%)$. The other disorders group was composed of cases having adjustment disorder $(n=7,3.2 \%)$, anxiety disorder $(n=4$, $2.8 \%)$, dissociative disorder $(n=7,3.2 \%)$, substance abuse $(\mathrm{n}=6,2.7 \%)$, and impulse control disorder - not otherwise specified $(n=10,5.0 \%)$.

Medication nonadherence of the study subgroups defined as bipolar disorder, schizophrenia/schizoaffective disorder, depression, and other disorders are shown in Table 2. Medication nonadherence was significantly higher in the bipolar disorder group when compared to other diagnostic groups $(12.1 \%, 18.2 \%$, and $24.2 \%$ vs $45.5 \% ; P<0.05)$.

Table 3 yielded the following results: items 2, 3, and 1 in bipolar disorder cases, item 2 in schizophrenia/schizoaffective disorder cases, item 4 in depression cases, and item 3 in cases diagnosed with other disorders were found to be significantly important in medication nonadherence.

When the effects of important demographic and clinical parameters listed in Table 4 were studied by regression analysis by taking medication nonadherence as the dependent variable, it was found that age, sex, marital status, education status, smoking, living with others, and place of residence had no significant effect on medication nonadherence $(P>0.05)$, while irregular follow-up attendance (odds ratio [OR]: 5.7; 95\% confidence interval [CI]: 2.92-11.31) and diagnosis (OR: 1.5; 95\% CI: 1.07-1.95) had increasing effects on medication nonadherence $(P<0.05)$.

\section{Discussion}

In the present study, cases hospitalized at the psychiatry clinic of our hospital were classified into bipolar disorder, 
Table 2 Medication nonadherence in bipolar disorder, schizophrenia/schizoaffective disorder, depression, and other disorder groups

\begin{tabular}{llllll}
\hline $\begin{array}{l}\text { Medication } \\
\text { nonadherence }\end{array}$ & $\begin{array}{l}\text { Bipolar disorder } \\
(\mathbf{n = 6 8 )}\end{array}$ & $\begin{array}{l}\text { Schizophrenia/schizoaffective } \\
\text { disorder }(\mathbf{n}=\mathbf{5 9})\end{array}$ & $\begin{array}{l}\text { Depression } \\
(\mathbf{n}=\mathbf{3 9})\end{array}$ & $\begin{array}{l}\text { Other } \\
(\mathbf{n}=\mathbf{3 7})\end{array}$ \\
\hline Present & $45(45.5 \%)$ & $24(24.2 \%)$ & $12(12.1 \%)$ & $18(18.2 \%)$ & $99(100 \%)$ \\
Absent & $23(22.1 \%)$ & $35(33.7 \%)$ & $27(26.0 \%)$ & $19(18.3 \%)$ & $104(100 \%)$ \\
\hline
\end{tabular}

Notes: Medication nonadherence was significantly higher in the bipolar group when compared to the other diagnostic groups $(P<0.05)$.

schizophrenia/schizoaffective disorder, depression, and other disorder groups, and medication nonadherence ratios during the last 6 months were examined together with the clinical factors affecting medication nonadherence. Sociodemographic features were found to have no effect on medication nonadherence. In the study group, the cases had bipolar disorder, schizophrenia/schizoaffective disorder, depression, and other disorders. The ratio of medication nonadherence was found to be higher in bipolar disorder group when compared to the schizophrenia/schizoaffective disorder, depression, and other disorder groups. Schizophrenia/schizoaffective disorder, depression, and other disorder groups had similar ratios in terms of medication nonadherence. Not willing to use medication, not accepting the disease, and being disturbed by side effects in the bipolar group; not accepting the disease in schizophrenia/schizoaffective disorder cases; feeling well in depression cases; and being disturbed by side effects in other disorder cases were the factors effecting medication adherence more when compared to other factors. In general, all the diagnostic groups were similar in terms of the ratio of preferring the other items. In logistic regression analysis, age, sex, marital status, education status, smoking, living with others, place of residence, irregular follow-up attendance, and diagnosis were evaluated as variables having the potential to effect medication adherence; of these irregular follow-up (OR: 5.7) and diagnosis (OR: 1.5) were found to be the only factors increasing medication nonadherence. The other variables were found to have no effect on medication adherence.

In a study conducted by Scott and Pope, the ratio and reasons of medication nonadherence (in mood stabilizers) were evaluated in 98 bipolar disorder cases. ${ }^{5}$ The authors reported the medication nonadherence ratio as $50 \%$ in the previous 2 years and stated that past history of nonadherence, lack of insight, and greater duration of using a medication were the factors significantly increasing medical nonadherence, while side effects were not as good as attitudes and behaviors in predicting medication nonadherence. Arvilommi et al studied clinical features with respect to their effects on medication nonadherence in an 18-month prospective study conducted on 168 in- and outpatients with bipolar disorders I and II. ${ }^{17}$ The authors found that half of the cases had medication nonadherence and reported that the main reasons for medication nonadherence were side effects, lack of motivation, and

Table 3 Feedback related to the reasons of medication nonadherence in bipolar disorder, schizophrenia/schizoaffective disorder, depression, and other diagnostic groups

\begin{tabular}{|c|c|c|c|c|}
\hline Items & $\begin{array}{l}\text { Bipolar disorder } \\
(n=45)\end{array}$ & $\begin{array}{l}\text { Schizophrenia/schizoaffective } \\
\text { disorder }(n=24)\end{array}$ & $\begin{array}{l}\text { Depression } \\
(n=12)\end{array}$ & $\begin{array}{l}\text { Other } \\
(n=18)\end{array}$ \\
\hline $\begin{array}{l}\text { Item I: Not willing to use } \\
\text { medication }\end{array}$ & 19 (23.2\%) & $6(15.85 \%)$ & $5(17.9 \%)$ & $7(25.9 \%)$ \\
\hline $\begin{array}{l}\text { Item 2: Not accepting the } \\
\text { disease }\end{array}$ & $23(32.9 \%)$ & $9(23.7 \%)$ & $5(17.9 \%)$ & $6(22.2 \%)$ \\
\hline $\begin{array}{l}\text { Item 3: Being disturbed by side } \\
\text { effects }\end{array}$ & $22(26.8 \%)$ & $4(10.5 \%)$ & $5(17.9 \%)$ & $8(29.6 \%)$ \\
\hline Item 4: Feeling well & II (I3.4\%) & 5 (I3.2\%) & $8(28.6 \%)$ & $3(11.1 \%)$ \\
\hline $\begin{array}{l}\text { Item 5: Not knowing how long } \\
\text { the medication would need to } \\
\text { be taken for }\end{array}$ & I (I.2\%) & $4(10.5 \%)$ & I (3.6\%) & 0 \\
\hline $\begin{array}{l}\text { Item 6: Not being aware that } \\
\text { the medication needed to be } \\
\text { taken regularly }\end{array}$ & 0 & $6(15.8 \%)$ & $2(7.1 \%)$ & $2(7.4 \%)$ \\
\hline Item 7: Other & $2(2.4 \%)$ & $4(10.5 \%)$ & $2(7.1 \%)$ & I (3.7\%) \\
\hline
\end{tabular}

Notes: Answers in each diagnostic group are shown as the number and percentage of cases representing each answer. The distribution of the items selected by the cases in a seven-item question - multiple answer questions answered as yes/no - examining the reasons of medication nonadherence was evaluated using multiple response analysis. The table yielded the following results: items I, 2, and 3 in bipolar disorder cases, item 2 in schizophrenia/schizoaffective disorder cases, item 4 in depression cases, and item 3 in cases diagnosed with other disorders were found to be significantly important in medication nonadherence. 
Table 4 Odds ratios of the selected demographic and clinical parameters that may affect medication nonadherence

\begin{tabular}{llll}
\hline $\begin{array}{l}\text { Dependent } \\
\text { variables }\end{array}$ & P-value & $\begin{array}{l}\text { Odds } \\
\text { ratio }\end{array}$ & $\begin{array}{l}\text { 95\% confidence } \\
\text { interval }\end{array}$ \\
\hline Age & 0.86 & 1.0 & $0.97-1.04$ \\
Sex & 0.44 & 1.3 & $0.65-2.73$ \\
Marital status & 0.77 & 0.9 & $0.6 \mathrm{I}-1.44$ \\
Education & 0.09 & 0.3 & $0.08-1.2 \mathrm{I}$ \\
Smoking & 0.50 & 1.3 & $0.63-2.58$ \\
Living with others & 0.37 & 0.8 & $0.58-1.23$ \\
Place of residence & 0.55 & 0.9 & $0.59-1.32$ \\
Irregular follow-up & $0.00 \mathrm{I}$ & 5.7 & $2.92-11.31$ \\
attendance & & & \\
Diagnosis & 0.01 & 1.5 & $1.07-1.95$ \\
\hline
\end{tabular}

Notes: Logistic regression analysis revealed that diagnosis and irregular followup attendance were the variables that had significant effects on medication nonadherence.

a negative attitude. Similar to the literature, we found that nearly half of the bipolar patients in our study had medication nonadherence. When the results of the above mentioned studies on bipolar disorders are taken into account, the reasons for medication nonadherence could be affected by various clinical parameters. In a review in which factors associated with adherence to treatment were comprehensively examined in bipolar patients, Leclerc et al classified the reasons of poor adherence as follows: patient-related factors (eg, younger age, male sex, low level of education, and alcohol and drugs comorbidity), treatment-related factors (eg, side effects of medications and effectiveness), and disorder-related factors (eg, younger age of onset, severity of $\mathrm{BD}$, insight, and lack of awareness of illness).$^{18}$ In our study we also aimed to evaluate the diagnostic groups as factors possible to be associated with medication nonadherence, the patientrelated factors defined by Leclerc et al were not evaluated based on diagnostic groups but as independent variables in logistic regression analysis of the whole study group. Nonetheless, consistent with literature, in bipolar patients, not willing to use medication, not accepting the disease, and being disturbed by side effects came into the forefront in our evaluation.

In a comprehensive review of recent literature, Lacro et al found a mean nonadherence rate of $49.5 \%$ in patients with schizophrenia. ${ }^{19}$ In our study, the ratio of medication nonadherence was found to be $24.2 \%$ in patients with schizophrenia. This could be related to difference in the study populations, methodology used in terms of definition and measurement of adherence, and period of time over which adherence was assessed. ${ }^{20}$ The ratio of regular medication use is higher in schizophrenia patients when compared to bipolar disorder patients $(50 \%-60 \%$ vs $35 \%){ }^{21}$ Similarly, in our study, the ratio of medication nonadherence was higher in bipolar disorder cases when compared to schizophrenia patients. In our study, the ratios of those denying their disease were $32.9 \%$ and $23.7 \%$ in bipolar and schizophrenia/schizoaffective disorder patients, respectively. Unal et al stated that $50 \%$ of the patients lost to follow-up after discharge or those having an irregular attendance to follow-up appointments did not have sufficient knowledge of their disorder. ${ }^{22}$ In another study, $68.5 \%$ of the patients were found to stop medication without physician approval due to experiencing side effects, believing the medication would not help them recover, and feeling well. ${ }^{23}$

We examined the reasons of medication nonadherence comprehensively, and observed that lack of insight was the major factor in those having bipolar disorder and schizophrenia/schizoaffective disorder (32.9\% and 23.7\%, respectively). In previous cross-sectional studies, it has been reported that patients with superior insight had better medication adherence when compared to those with no insight into their illness. ${ }^{24,25}$ Increasing insight has been shown to improve medication adherence. ${ }^{26}$ There may be varying levels of disease awareness, especially in psychotic patients. In another study, it was found that treatment compliance is not related to awareness of mental diseases but is related to an increased awareness of clinical symptoms. ${ }^{27}$

It has been reported that one out of every three patients (34.2\%) having a chronic psychiatric disorder attends follow-up appointments regularly. ${ }^{23}$ Low socioeconomic status, younger age, low educational level, history of irregular follow-up, substance abuse, low functioning, serious psychiatric problems, problems with communication with their physician, and living far away from treatment centers have been found to be associated with irregular follow-up..$^{16,17}$ Not attending follow-up appointments after the first episode can be an indicator of medication adherence. ${ }^{22}$ Medication adherence can be controlled by asking patients to bring their medications with them to the follow-up appointments. ${ }^{10}$ The results obtained in our study and in previous studies suggest that follow-up appointments contribute to patient-physician relations and support medication adherence by increasing insight into illness.

The strengths of our study are having several diagnostic groups and analyzing medication adherence from multiple perspectives. Moreover, a different point of view is presented by studying the history of medication nonadherence in inpatients. Limitations of our study include: the number of cases in diagnostic groups being relatively less than the number of characteristics studied, having a population composed of only 
inpatients, and being a cross-sectional study. Starting out from this point, further prospective studies conducted on outpatients, having a larger study population where the patients are followed-up for a longer time, and including a control group are suggested to be performed.

In conclusion, the ratio of medication nonadherence is high in patients hospitalized at a university hospital setting for bipolar disorder, schizophrenia/schizoaffective disorder, depression, and other disorders. Medication nonadherence affects treatment success significantly more in bipolar disorder and cases with irregular attendance to follow-up appointments. Views of psychiatric patients on medication nonadherence may contribute to determining strategies to increase medication adherence and to organize trainings for patients and families to decrease medication nonadherence. In the present study, medication nonadherence was evaluated through self-report, statements of relatives, and information on patient files. It is recommended to evaluate medication adherence in future studies through more specific methods such as pill counting and biochemical analysis along with the methods used in the present study. Also, further studies are needed that score medication nonadherence in bipolar disorder, schizophrenia/schizoaffective disorder, and depression patients using a new scale specific for psychiatric patients and in terms of giving direction to the practice of reducing the medication nonadherence.

\section{Acknowledgments}

The authors wish to thank all patients and nursing staff involved in the study.

\section{Disclosure}

The authors report no conflicts of interest in this work.

\section{References}

1. Crowe M, Wilson L, Inder M. Patients' reports of the factors influencing medication adherence in bipolar disorder - an integrative review of the literature. Int J Nurs Stud. 2011;48(7):894-903.

2. Chapman SC, Horne R. Medication nonadherence and psychiatry. Curr Opin Psychiatry. 2013;26(5):446-452.

3. Patel MX, David AS. Medication adherence: predictive factors and enhancement strategies. Psychiatry. 2007;6(9):357-361.

4. Zygmunt A, Olfson M, Boyer CA, Mechanic D. Interventions to improve medication adherence in schizophrenia. Am J Psychiatry. 2002;159(10):1653-1664.

5. Scott J, Pope M. Nonadherence with mood stabilizers: prevalence and predictors. J Clin Psychiatry. 2002;63(5):384-390.

6. Pampallona S, Bollini P, Tibaldi G, Kupelnick B, Munizza C. Patient adherence in the treatment of depression. Br J Psychiatry. 2002;180:104-109.

7. Kelleci M, Ata EE. Psikiyatri Kliniği’nde Yatan Hastaların ilaç Uyumları ve Sosyal Destekle Ilişkisi. [Drug compliance of patients hospitalized in the psychiatry clinic and the relationship with social support]. J Psy Nurs. 2011;2(3):105-110. Turkish [with English abstract].
8. Yilmaz S, Buzlu S. Antipsikotik kullanan hastalarda ilaç yan etkileri ve ilaç uyumu. [Side effects of medications and adherence to medication in patients using antipsychotics]. $\dot{l} \ddot{U} F$ N Hem Derg. 2012;20(2):93-103. Turkish [with English abstract].

9. Thompson L, McCabe R. The effect of clinician-patient alliance and communication on treatment adherence in mental health care: a systematic review. BMC Psychiatry. 2012;12:87.

10. Breen R, Thornhill JT. Noncompliance with medication for psychiatric disorders. CNS Drugs. 1998;9(6):457-471.

11. American Psychiatric Association. Diagnostic and Statistical Manual of Mental Disorder. 5th ed. Arlington, VA: American Psychiatric Association; 2013:726-727.

12. Sin J, Gamble C. Managing side-effects to the optimum: valuing a client's experience. J Psychiatr Ment Health Nurs. 2003;10(2):147-153.

13. Sarandol A, Akkaya C, Cangur S, Mercan S, Pirinççi E, Kirli S. Ayaktan takip edilen şizofreni hastalarının takip sürelerini etkileyen sosyodemografik, hastalık ve tedaviye ait özellikler. [Sociodemographic, disorder and treatment related characteristics affecting follow-up periods of schizophrenic outpatients]. Klinik Psikofarmakoloji Bülteni. 2007;17(1):15-23. Turkish [with English abstract].

14. First MB, Gibbon M, Spitzer RL, Williams JB. SCID-I. Structured Clinical Interview for DSM-IV-TR Axis I Disorders, Research Version, Patient Edition (SCID-I/P). New York, NY: Biometrics Research; 2001.

15. Olfson M, Mechanic D, Hansell S, Boyer CA, Walkup J, Weiden PJ. Predicting medication noncompliance after hospital discharge among patients with schizophrenia. Psychiatr Serv. 2000;51(2):216-222.

16. Coodin S, Staley D, Cortens B, Desrochers R, McLandress S. Patient factors associated with missed appointments in persons with schizophrenia. Can J Psychiatry. 2004;49(2):145-148.

17. Arvilommi P, Suominen K, Mantere O, Leppämäki S, Valtonen H, Isometsä E. Predictors of adherence to psychopharmacological and psychosocial treatment in bipolar I or II disorders - an 18-month prospective study. $J$ Affect Disord. 2014;155:110-117.

18. Leclerc E, Mansur RB, Brietzke E. Determinants of adherence to treatment in bipolar disorder: a comprehensive review. J Affect Disord. 2013;149(1-3):247-252.

19. Lacro JP, Dunn LB, Dolder CR, Leckband SG, Jeste DV. Prevalence of and risk factors for medication nonadherence in patients with schizophrenia: a comprehensive review of recent literature. J Clin Psychiatry. 2002;63(10):892-909.

20. Haddad PM, Brain C, Scott J. Nonadherence with antipsychotic medication in schizophrenia: challenges and management strategies. Patient Relat Outcome Meas. 2014;5:43-62.

21. Javadpour A, Hedayati A, Dehbozorgi GR, Azizi A. The impact of a simple individual psycho-education program on quality of life, rate of relapse and medication adherence in bipolar disorder patients. Asian $J$ Psychiatr. 2013;6(3):208-213.

22. Unal S, Cakır G, Elyas Z. Taburculuk sonrası tedaviye gelmeyen psikotik hastaların özellikleri. [Characteristics of psychotic patients don't come to appointments]. Anadolu Psikiyatri Dergisi. 2006;7:69-75. Turkish [with English abstract].

23. Tel H, Doğan S, Özkan B, Çoban S. Compliance to treatment among chronic psychiatric disorder patients according to their relatives. Psikiyatri Hemşireliği Dergisi. 2010;1(1):7-12.

24. Nageotte C, Sullivan G, Duan N, Camp PL. Medication compliance among the seriously mentally ill in a public mental health system. Soc Psychiatry Psychiatr Epidemiol. 1997;32(2):49-56.

25. McEvoy JP, Apperson LJ, Appelbaum PS, et al. Insight in schizophrenia. Its relationship to acute psychopathology. J Nerv Ment Dis. 1989;177(1):43-47.

26. Kemp R, Kirov G, Everitt B, Hayward P, David A. Randomised controlled trial of compliance therapy. 18-month follow-up. Br J Psychiatry. 1998;172:413-419.

27. Kelly GR, Scott JE, Mamon J. Medication compliance and health education among outpatients with chronic mental disorders. Med Care. 1990;28(12):1181-1197. 
Patient Preference and Adherence

Dovepress

\section{Publish your work in this journal}

Patient Preference and Adherence is an international, peer-reviewed, open access journal that focuses on the growing importance of patient preference and adherence throughout the therapeutic continuum. Patient satisfaction, acceptability, quality of life, compliance, persistence and their role in developing new therapeutic modalities and compounds to optimize

Submit your manuscript here: http://www.dovepress.com/patient-preference-and-adherence-journa clinical outcomes for existing disease states are major areas of interest for the journal. This journal has been accepted for indexing on PubMed Central. The manuscript management system is completely online and includes a very quick and fair peer-review system, which is all easy to use. Visit http://www. dovepress.com/testimonials.php to read real quotes from published authors. 